\title{
PRACTICAL IMPLEMENTATION OF REPETITION CODES
}

\author{
Paulo Jorge Dias Torres ${ }^{1}$, Sérgio Miguel Nunes Malhão \\ 1,2 Instituto Politécnico de Castelo Branco \\ Escola Superior de Tecnologia \\ paulo.torres@ipcb.pt,smalhao@ipcbcampus.pt
}

\begin{abstract}
This work consists in the development of software with the main objective of increasing the quality of the communication system with Repetition Codes and GFSK modulation. To evaluate the probability of error we used simulation in software Python and implemented with hardware (Raspberry Pi, Arduino and transceiver NRF24L01).
\end{abstract}

Keywords: Arduíno, Raspberry Pi, Python, NRF24L01+, GFSK.

\section{Introduction}

Digital code theory began in the late 1940s with the works of Golay, Hamming and Shannon. Since then, a great effort has been made to obtain efficient codes, and the use of digital codes goes through the coding and decoding processes, which is usually the most difficult of the two.

The most studied codes are the cyclic codes, as these are the easiest to encode, supporting an algebraic structure, allowing to find various methods of decoding. In addition, they include an important family of codes, which are the Bose, Chaudhuri, Hocquenghem (BCH) codes, which are the generalization of the Hamming codes for multiple error correction. The importance of BCH codes is as much the smaller the "number of errors expected" vs "code block length".

However, there is also a simple procedure to decode these codes. In coding theory, the repetition code is one of the most basic error-correction codes. To transmit a message through a channel with noise that may corrupt the transmission in some places, the idea of the repetition codes is just repeat the message several times. The hope is that the channel corrupts only a minority of these repetitions, and in this way, the receiver will notice that a transmission error occurred, since the data flow received is not the repeat of a single message and in addition, the receiver can recover the original message by observing the message received in the data stream that occurs more often.
The aim of this study was to study and evaluate the probability of error in the real context of a radiofrequency transmission through the Gaussian Frequency Shift Keying (GFSK), with the application of repetition codes to correct errors to compare the communication quality with the situation without correction of errors, both in the theoretical context and in the real context. We used Arduino and Raspberry PI with transceiver NRF24L01+, in the practical experiments, with transceiver NRF24L01+[1].

\section{BFSK Modulation}

An important performance measure used for digital modulation schemes is the likelihood of error, since it is associated with the probability measure of the detector causing it to assimilate a wrong decision on the transmitted symbol. The probability of error can be obtained through the following expression:

$$
P_{e}=Q\left(\sqrt{\frac{E_{d}}{2 N_{0}}}\right)
$$

were:

$$
E_{d}=\int_{0}^{T}\left[s_{1}(t)-s_{2}(t)\right]^{2} d t
$$

That is, the energy of the difference signal:

$$
\begin{aligned}
& E_{d}=\int_{0}^{T} s_{1}^{2}(t) d t-2 \int_{0}^{T} s_{1}(t) s_{2}(t) d t+\int_{0}^{T} s_{2}^{2}(t) d t \leftrightarrow \\
& \leftrightarrow E_{d}=E_{b}-2\left\|s_{1}\right\|\left\|s_{2}\right\| \cos (\theta)+E_{b} \leftrightarrow \\
& \leftrightarrow E_{d}=2 E_{b}-2 \sqrt{E_{b}} \sqrt{E_{b}} \cos (\theta)+E_{b} \leftrightarrow \\
& \leftrightarrow E_{d}=2 E_{b}-2 E_{b} \cos (\theta) \leftrightarrow \\
& \leftrightarrow E_{d}=2 E_{b}(1-p)
\end{aligned}
$$


where $\rho=\cos (\theta)$ is a normalized correlation between $s_{1}(t)$ and $s_{2}(t)$ for $-1 \leq \rho \leq 1$

This way:

$$
\begin{aligned}
& P_{e}=Q\left(\sqrt{\frac{E_{d}}{2 N_{0}}}\right) \leftrightarrow \\
& \leftrightarrow P_{e}=Q\left(\sqrt{\frac{2 E_{b}(1-\rho)}{2 N_{0}}}\right)
\end{aligned}
$$

Case:

$$
\begin{aligned}
& \rho=0 \text { so } \theta=\frac{\pi}{2} \rightarrow B F S K \rightarrow \\
& \rightarrow P_{\theta}=Q\left(\sqrt{\frac{E_{b}}{N_{0}}}\right)
\end{aligned}
$$

Constituting itself as the expression of the probability of error for coherent BFSK, the following:

$$
P_{e}=Q\left(\sqrt{\frac{E_{b}}{N_{0}}}\right)
$$

\section{Channel Coding}

A designer of a digital communication system, faces the task of providing a system, both in economic terms, as well as, in terms of a rate, level of reliability and quality in the communication system. Two essential parameters, are the signal power and the bandwidth, which in conjunction with the spectral density of the channel noise, determine the spectral density of power (Eb/N0). In practice, it is usually used to modify the quality of the data, as well as to obtain na acceptable quality, to do so, the coding of error control is used. Another incentive to use coding is to reduce the $E b / N 0$, being this reduction exploited by the reduction of transmitted power and reduction of hardware costs.

Error control, it is used in order to obtain the integrity of the data and can be executed through direct error correction Forward Error Correction (FEC), i.e. the discrete font, generates information in the form of binary symbols, in which the channel encoder on the transmitter accepts the message bits with redundancy, according to a predefined rule, thus producing data encoded at a higher bit rate, already the decoder in receiver, will exploit the redundancy in order to decide which bits of the message were transmitted.

The goal of the encoder and decoder is to minimize the noise effect on the channel[2][3].

\subsection{Repetition Code}

It can be said that the repetition code is one of the most basic codes of error correction with linear block codes, and the idea of this code is to repeat several times the message transmitted to minimize the errors in the transmission of the message, retrieving the original message observing the message received in the data stream more frequently[4][3].

The probability of error for this code, with $t=\frac{n-1}{2}, d_{\min }=2 t+1$ and $C_{k}^{n}=\frac{n !}{k !(n-k) !}$ ? is obtained through the following relationship:

$$
P_{\text {repet }}=\sum_{i=t+1}^{n} C_{i}^{n} p(1-p)^{n-i} \cong C_{t+1}^{n} p^{t+1}
$$

\subsection{Building the code}

The construction of the code vector, is given by, $c=[b \mid m]$ in which $\mathrm{b}$ is the parity bits and the message bits, replacing in the equation and factoring the vector $m$ of the message we have $c=\left[P \mid I_{k}\right]$, where $I_{k}$ is the identity matrix $k$ by $n$ :

$$
P=\left[\begin{array}{ccc}
1 & p_{00} & p_{0, n-k-1} \\
1 & p_{11} & p_{1 n-k-1} \\
\vdots & \vdots & \vdots \\
1 & p_{k-1,1} & p_{k-1, n-k-1}
\end{array}\right]
$$

Defining the generating array $(G)$ its canonical form through the relationship $G=\left[P \mid I_{k}\right]$, already your parity matrix $(H)$ is given by the following relationship $H=\left[I_{[n-k)} \mid P^{T}\right]$. Both the generating matrix and the parity matrix are fundamental in describing a linear block code[2].

\subsection{Examples of Repetition Codes}

We will present examples of repetition codes (3, $1),(5,1)$ used in this work. For the above codes, through its generator polynomials we will be able to build its generating matrix and parity matrix. The polynomial generator for repeat code $(n=3, k=1)$ is concretly $g(X)=1+x+x^{2}$, being its generating matrix $G=\left[\begin{array}{lll}1 & 1 & 1\end{array}\right]$ and its parity matrix $(H)$ :

$$
H=\left[\begin{array}{lll}
1 & 0 & 1 \\
0 & 1 & 0
\end{array}\right]
$$

In the Fig. 1 we can observe the value of the minimum distance of Hamming, that is, the minimum distance value of Hamming for all pairs of code words (Table 1). 


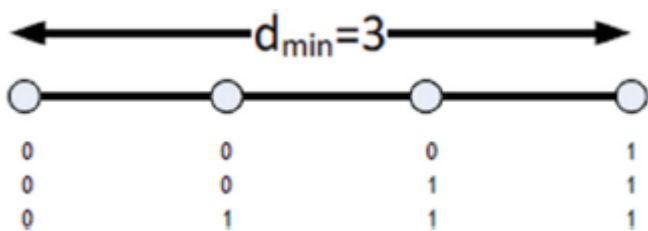

Figure 1: Minimum distance for repetition code 3.

The polynomial generator for repeat code $(n=5, k=$ 1 ) is concretly $g(X)=1+X+X^{2}+X^{3}+X^{4}$, being its generating matrix $G=\left[\begin{array}{lllll}1 & 1 & 1 & 1 & 1\end{array}\right]$, and its parity matrix:

$$
H=\left[\begin{array}{lllll}
1 & 0 & 0 & 0 & 1 \\
0 & 1 & 0 & 0 & 1 \\
0 & 0 & 1 & 0 & 1 \\
0 & 0 & 0 & 1 & 1
\end{array}\right]
$$

Similarly, the minimum distance of Hamming for this code was observed by the following Fig. 2.

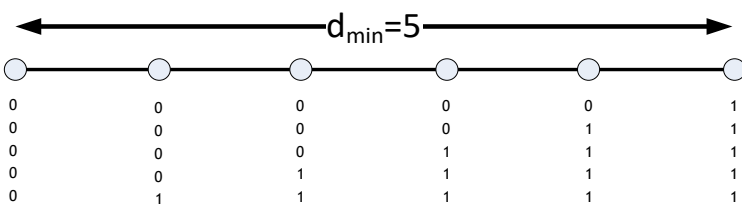

Figure 2: Minimum distance for repetition code 5.

Table 1. Comparison table between the repetition codes with $k=1$ and $\frac{E_{b}}{N_{0}}=9.54 \mathrm{~dB}$.

\begin{tabular}{|c|c|c|}
\hline $\begin{array}{c}\text { Code } \\
\text { Characteristics }\end{array}$ & Code 1 & Code 2 \\
\hline $\begin{array}{c}\text { Message Length } \\
(k)\end{array}$ & 1 & 1 \\
\hline $\begin{array}{c}\text { Length of the } \\
\text { word code }(n)\end{array}$ & 3 & 0.2 \\
\hline $\begin{array}{c}\text { Coding rate } \\
\left(R=\frac{k}{n}\right)\end{array}$ & 0.333 & 5 \\
\hline $\begin{array}{c}\text { Minimum distance } \\
\left(d_{\text {min }}\right)\end{array}$ & 2 & 4 \\
\hline $\begin{array}{c}\text { Error detection } \\
\text { capability }\end{array}$ & 1 & 2 \\
\hline $\begin{array}{c}\text { Error correction } \\
\text { capability }(t)\end{array}$ & $6.75 \times 10^{-6}$ & $3.38 \times 10^{-8}$ \\
\hline $\begin{array}{c}\text { Probability of } \\
\text { error }\left(P_{b}\right)\end{array}$ & & \\
\hline
\end{tabular}

\section{Hardware}

\subsection{Transceiver NRF24L01+}

The module used as the basis for the development of this work was the integrated circuit NRF24L01+, being this produced by Nordic Semiconductor[5]. Developed for wireless applications that uses the protocol Enhanced ShockBurstTM in your data link layer. It is set up through the Serial Peripheral Interface (SPI) using up to 128 different channels of bandwidth $1 \mathrm{MHz}$, is designed to operate in the band of $2.4 \mathrm{GHz}$ of Industrial, Scientific and Medical (ISM).

This module consists of an integrated antenna, however, there is the same module with exterior antenna, connectors and other passive components. We will be able to observe some of the characteristics of the module NRF24L01+ in Fig. 3 and Table 2[5].

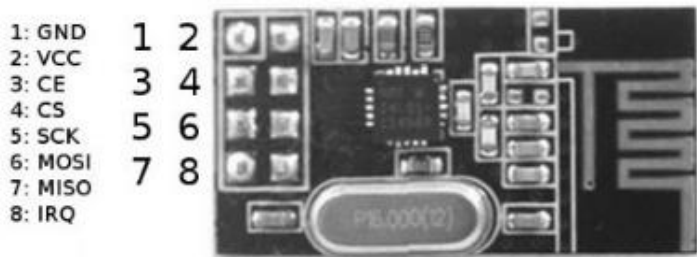

Figure 3: Pinout TransceiverNRF24L01+[6].

Table 2. Characteristics of the NRF24LO1+ [5].

\begin{tabular}{|c|c|}
\hline Parameters & Typical values \\
\hline Feeding voltage & $1.9 \mathrm{~V}$ a $3.6 \mathrm{~V}(3.3 \mathrm{~V})$ \\
\hline Power current & $1 \mu \mathrm{A}$ \\
\hline $\begin{array}{c}\text { Frequency of } \\
\text { operation }\end{array}$ & $2.4 \mathrm{GHz}$ \\
\hline Transmission Rates & 256kbps, $1 \mathrm{Mbps}$ ou $2 \mathrm{Mbps}$ \\
\hline Modulation type & GFSK \\
\hline Communication & 126 RF Channel \\
\hline $\begin{array}{l}\text { Current (TX) to } \\
\text { 0dBm }\end{array}$ & $11.3 \mathrm{~mA}$ \\
\hline $\begin{array}{c}\text { Current }(\mathrm{RX}) \text { to } \\
2 \mathrm{Mbps}\end{array}$ & $13.5 \mathrm{~mA}$ \\
\hline Current at rest & $900 \mathrm{nA}$ \\
\hline $\begin{array}{c}\text { Programmable } \\
\text { Transmission } \\
\text { Power } \\
\end{array}$ & $0,-6,-12,-18 d B m$ \\
\hline $\begin{array}{c}\text { Reception } \\
\text { sensitivity with a } \\
\text { BER of } 0.1 \% \text { to } \\
2 \mathrm{Mbps}\end{array}$ & $-82 \mathrm{dBm}$ \\
\hline Buffer & $\begin{array}{c}1 \text { to } 32 \text { bytes of data at a } \\
\text { time }\end{array}$ \\
\hline $\begin{array}{c}\text { Working } \\
\text { temperature }\end{array}$ & $-40^{\circ}$ a $85^{\circ}$ \\
\hline Transmission range & $\begin{array}{c}100 \mathrm{~m} \text { in free space } \\
1 \mathrm{~km} \text { with outdoor } \\
\text { antenna }\end{array}$ \\
\hline SPI & $\begin{array}{l}4 \text { pins, Max: } 10 \mathrm{Mbps}, 3 \\
\text { separate } 32 \text { bytes } \\
\text { TX and RX FIFOs (first In } \\
\text { first Out) }\end{array}$ \\
\hline
\end{tabular}

\subsection{Arduíno}

Arduino is an open source platform and is used for the construction of electronic projects. This platform consists of a physical programmable hardware board (micro-controller) and an Integrated Development Environment (IDE) software, which is the software 
used to develop and load the code for Arduino. The Arduino IDE uses a simplified version of the $\mathrm{C}++$ software language, and we can observe some of the characteristics of Arduino. We will be able to observe some of the characteristics of the Arduíno board in Fig. 4 and Table 3[7].

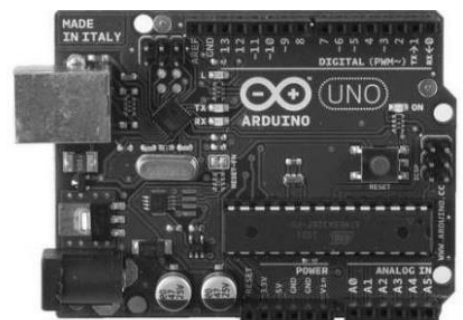

Figure 4: Arduíno UNO Board[7].

Table 3. Characteristics of Arduíno[7].

\begin{tabular}{|c|c|}
\hline Model & Arduíno UNO \\
\hline Microcontroller & ATMEGA328p \\
\hline Operating voltage & $5 \mathrm{~V}$ \\
\hline $\begin{array}{c}\text { Input voltage } \\
\text { (recommended) }\end{array}$ & $7-12 \mathrm{~V}$ \\
\hline $\begin{array}{l}\text { Input voltage } \\
\text { (Limits) }\end{array}$ & $6-20 \mathrm{~V}$ \\
\hline Digital pins I/O & $\begin{array}{l}14 \text { (of which } 6 \text { can be } \\
\text { PWM outputs) }\end{array}$ \\
\hline Analog Input Pins & 6 \\
\hline Serial Port & 1 \\
\hline $\begin{array}{c}\text { DC current by pin } \\
\text { I/O }\end{array}$ & $40 \mathrm{~mA}$ \\
\hline $\begin{array}{c}\text { DC Current for pin } \\
3,3 \mathrm{v}\end{array}$ & $50 \mathrm{~mA}$ \\
\hline Flash Memory & $\begin{array}{c}32 \text { KB (ATMEGA328) of } \\
\text { which } 0,5 \text { KB are used by } \\
\text { the bootloader }\end{array}$ \\
\hline SRAM & 2 KB (ATMEGA328) \\
\hline EEPROM & 1 KB (ATMEGA328 \\
\hline Clock speed & $16 \mathrm{MHz}$ \\
\hline
\end{tabular}

\subsection{Raspberry Pi}

The Raspberry Pi is essentially a small computer, developed in the UK, by the Raspberry $\mathrm{Pi}$ Foundation. This is made up of a hardware board, developed with

the aim of promoting the teaching of basic programming sciences at school level. This is a relatively easy-to-use platform with a multitude of uses in the most diverse areas. Similarly, to Arduino, this is made up of two parts, hardware and software. The software to be used with Raspberry Pi, is the Raspbian operating system, which is based on Debian (Linux) optimized for the Raspberry PI hardware. We can observe some of the characteristics of Arduino. We will be able to observe some of the characteristics of the Arduíno board in Fig. 5 and Table 4 [8].

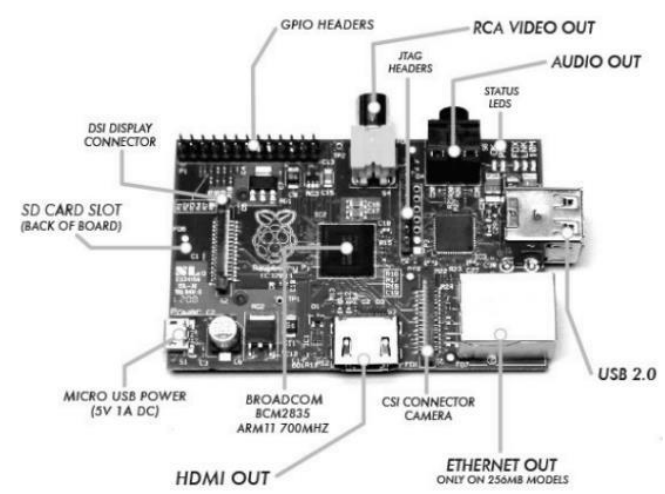

Figure 5: Raspberry Pi B Board[8].

Table 4. Characteristics of Raspberry Pi B [8].

\begin{tabular}{|c|c|}
\hline Model & Raspberry Pi B \\
\hline CPU & $\begin{array}{c}700 \mathrm{MHz} \text { ARM1176JZF-S core } 32 \\
\text { bits }\end{array}$ \\
\hline GPU & $\begin{array}{c}\text { Broadcom VideoCore IV @ } 250 \\
\text { MHZ }\end{array}$ \\
\hline Power & $5 \mathrm{~V}-2 \mathrm{~A}$ \\
\hline HDMI Port & 1 \\
\hline $\begin{array}{l}\text { Memory } \\
\text { Ram }\end{array}$ & $512 \mathrm{MB}$ \\
\hline $\begin{array}{l}\text { USB Port } \\
2.0\end{array}$ & 2 \\
\hline Storage & SD Card \\
\hline $\begin{array}{c}\text { Ethernet } \\
\text { Port }\end{array}$ & $\begin{array}{c}1(10 / 100 \text { BaseT Ethernet } \\
(\mathrm{RJ} 45)\end{array}$ \\
\hline $\begin{array}{l}\text { Video } \\
\text { output }\end{array}$ & $\begin{array}{l}\text { Composite RCA (PAL \& NTSC), } \\
\text { HDMI and LCD panels via DSL }\end{array}$ \\
\hline $\begin{array}{l}\text { Audio } \\
\text { output }\end{array}$ & $3.5 \mathrm{~mm}$ connector, HDMI \\
\hline GPIO Pins & 26 \\
\hline Dimensions & $85.6 \times 53.98 \times 17 \mathrm{~mm}$ \\
\hline
\end{tabular}

\section{Practical Results}

In the following figures we will be able to observe the way the hardware was interconnected (see Fig. 6 and Fig. 7). To develop this work, we used Python scripts with and without repetition code. To compare the theoretical with practical results we evaluate the probability of error with GFSK modulation (NRF24L01+) (see Fig. 8 and Fig. 9)[9]. In Arduino we used a script developed in $C / C++$, with data to transmit through NRF24L01+. It is intended that when the data were received in the receiver, the errors were corrected and at the same time it could obtain the number of errors in the receiver that were obtained with the transmission of 1000 words. 
We will be able to observe through the Fig. 10 and Fig. 11 how the hardware interconnection was performed through the diagram of blocks presented, as well as its interconnection in a real context[9].

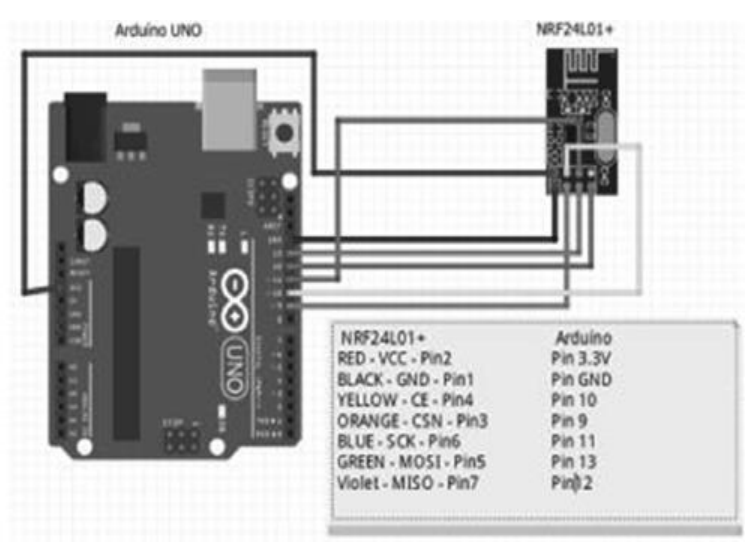

Figure 6: Link scheme between NRF24L01+ and Arduino

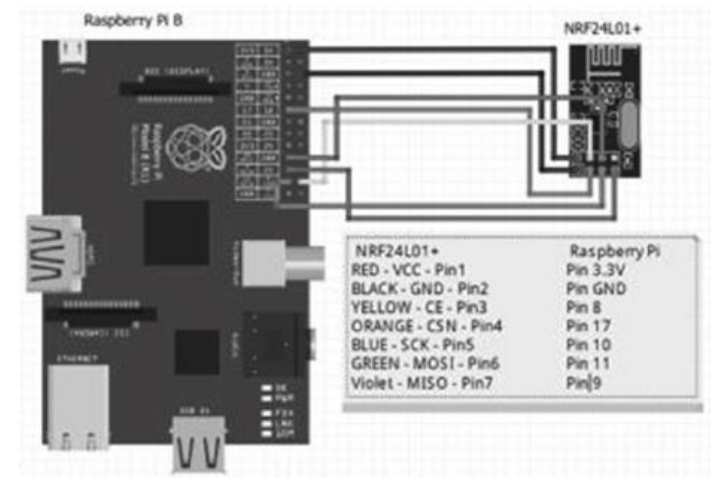

Figure 7: Link scheme between NRF24LO1+ and Raspberry Pi B

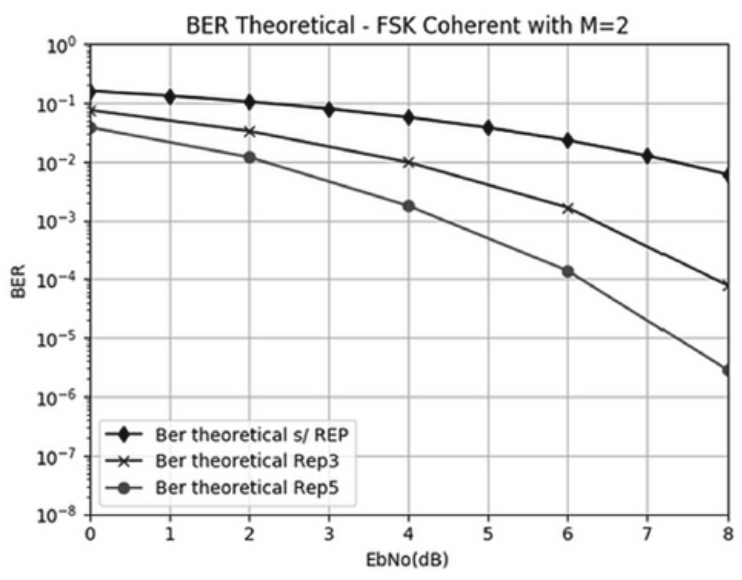

Figure 8: Error probability with and without repetition codes for theoretical values

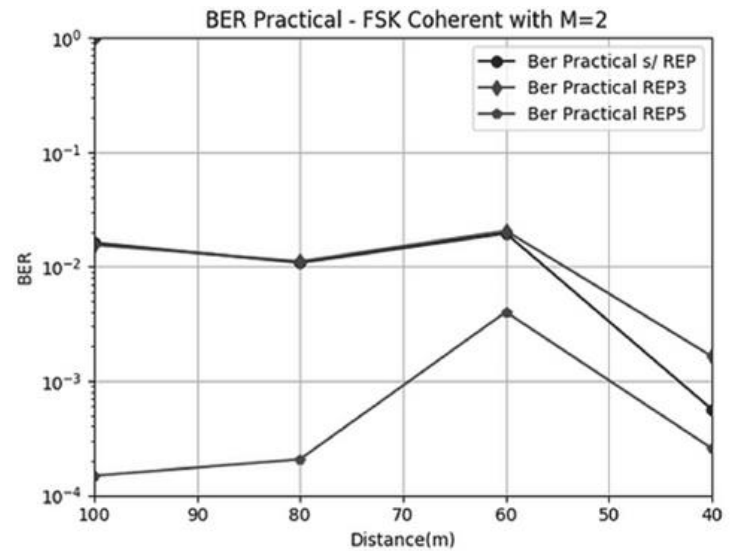

Figure 9: Error probability with and without repetition codes for practical values

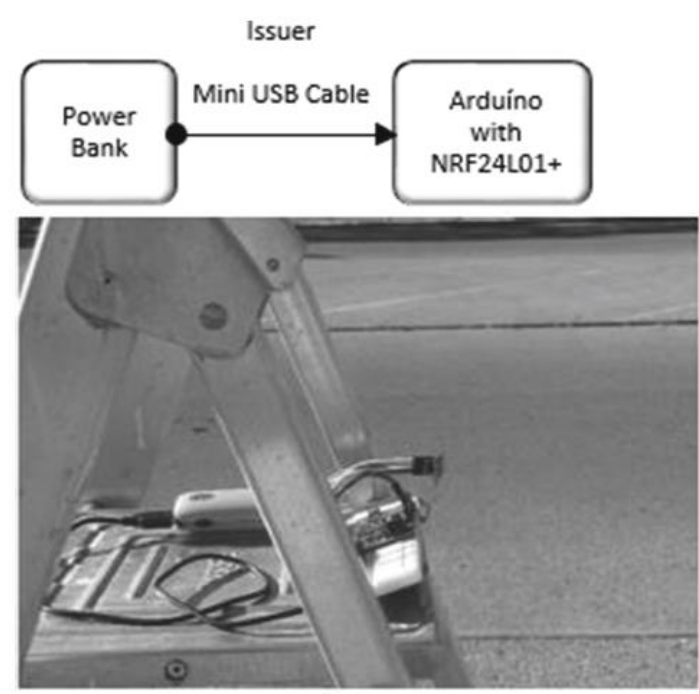

Figure 10: Issuer in a real environment

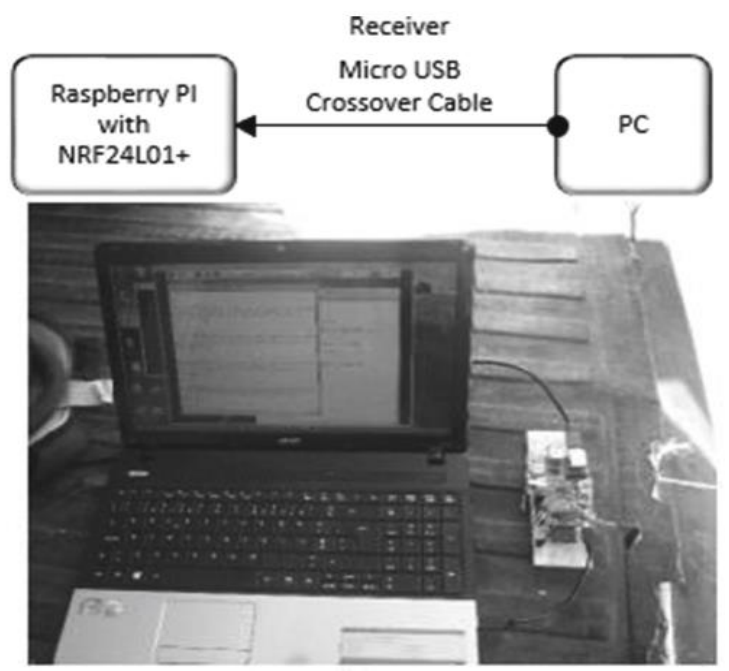

Figure 11: Receiver in a real environment 


\section{Conclusions}

More than ever the coding and correction of errors in transmissions, it is fundamental in a telecommunications system, notably the need for encryption, the combination of various sources of different debts, for example. It is necessary and indispensable to know the various types of error correction codes as well as their development at the software level.

With the realization of this work we can understand the development of error correction codes, since they have some complexity in their development, hence the importance to know them as we can see in Fig. 4.

We can improve the quality of the communication system, with repetition codes with a higher number of repetitions (for example 7 repetitions) but the transmission rate will decrease.

However, when it came to the realization the practical tests were observed some influences at the level of transmission between the transmitter and the receiver, namely the temperature, the wind, and the relative humidity of the air, since, these parameters in some way influence.

\section{References}

[1] M. da C. R. Trancoso, Sestematização da Codificação e Discodificação de Codigos BCH. FEUP, 1995.

[2] S. Haykin, Communication Systems, 4th ed. 2001.

[3] Marcio Doniak, "CDI - Comunicação Digital Demodulação em Banda Passante," pp. 1-44.

[4] P. G. Moreira, Jorge Castiñeira. Farrell, ESSENTIALS OF ERROR-CONTROL CODING. 2006.

[5] "nRF24L01 Single Chip 2.4GHz Transceiver Product Specification."

[6] P. Product and K. Features, "nRF24L01+ Datasheet," 2008.

[7] F. e Linhares and B. Pires, Controlo de um carro elétrico através de Arduíno. 2016.

[8] "IBEX Electronic Product Design Specialist." [Online]. Available: http://www.raspberryprojects.com/pi/category/pihardware/raspberry-pi-2-model-b.

[9] Paulo Torres and S. Malhão(2019) Error Correction Repetition Codes with Arduino and Raspberry PI. In: Machado J., Soares F., Veiga G. (eds) Innovation, Engineering and Entrepreneurship. HELIX 2018. Lecture Notes in Electrical Engineering, vol 505. Springer, Cham, 2019.

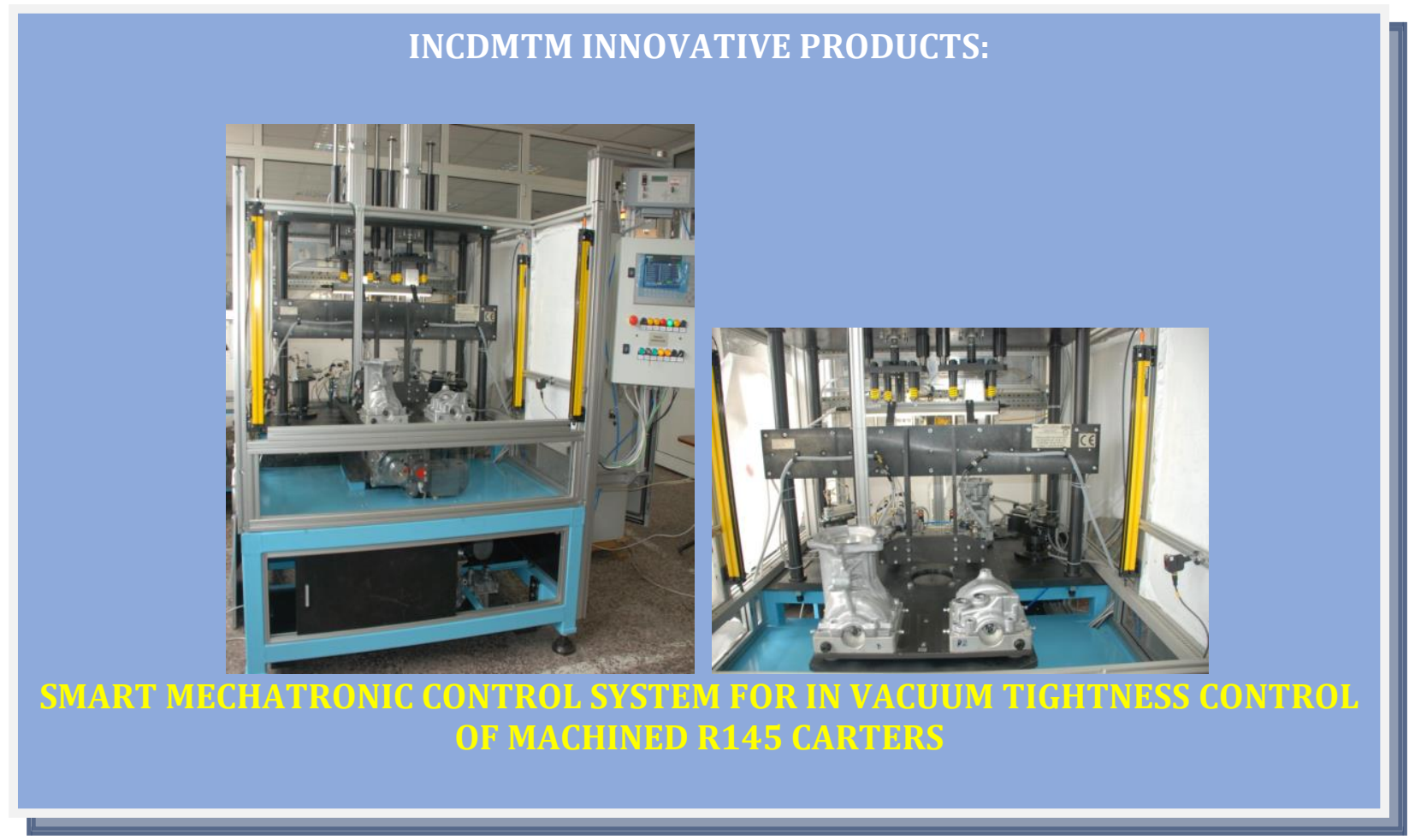

